\title{
LA CIUDAD COMO LUGAR
}

José María Silvestro Geuna, Dr. Arquitecto

$\mathrm{C} /$ Ermita de Bellvitge $546^{\circ} 1^{\text {a }}$, Hospitalet de Llobregat

Barcelona, 08907. Eapaña

\section{Josep Roca Cladera}

Catedrático de Arquitectura Legal Derecho Urbanístico y Valoraciones. ETSAB

Barcelona, España

Este artículo está fundamentado en una investigación doctoral recientemente culminada y que lleva por título: "La ciudad en busca del lugar: Una mirada interpretativa a la luz de las experiencias de Barcelona"; tesis desarrollada por el Dr. Arquitecto José María Silvestro Geuna y dirigida por el Dr. Arquitecto Josep Roca i Cladera, catedrático de la Escuela Superior de Arquitectura de Barcelona de la Universidad Politécnica de Cataluña (UPC).

Remisión Artículo: 27-1-2007

Palabras Claves: ciudad y arquitectura, habitar urbano, lugar y no lugar, responsabilidad profesional del arquitecto.

\section{Resumen:}

El tema que a continuación se desarrolla busca analizar desde la arquitectura y la actividad del arquitecto -en especial en el ámbito de la construcción del espacio- la importancia del concepto del lugar en la ciudad, entendido éste como el espacio más personal del ser humano, es decir, como su "hogar" en su sentido más propio y más extenso.

En este contexto, la temática escogida se convierte en un reto a la hora de reflexionar en la ciudad desde la perspectiva del lugar a partir del mismo hecho del habitar humano- para intentar desde ahí arrojar luz sobre la propia actividad del arquitecto, orientada a crear espacios que permitan la humanización de las personas. Desde este ángulo, el habitar humano -el lugar personal del hogar - no se agota a los ámbitos más propios y próximos (la vivienda o el espacio laboral) sino que, trascendiendo también éstos, busca interpretar y construir otros más amplios (la ciudad en su conjunto) desde un específico habitar urbano.

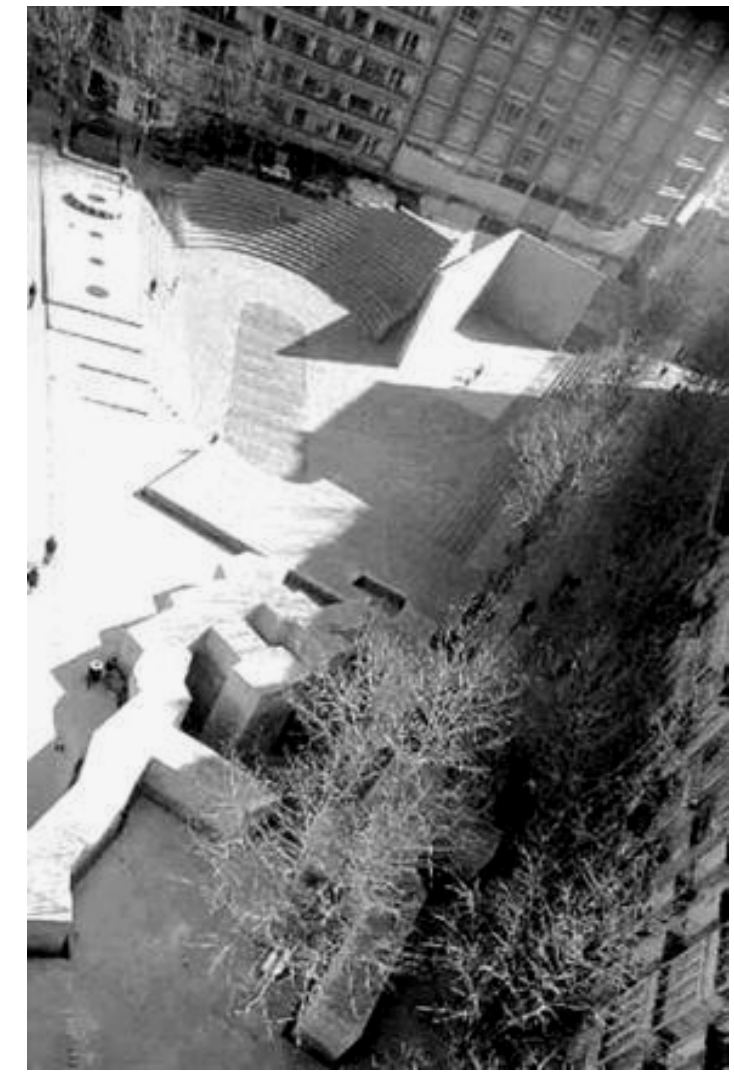

Figura 0:Foto de Plaza de los Fueros, Vitoria de Eduardo Chillida y Luís Peña-Ganchegui 


\section{Aproximación al tema}

Al reflexionar acerca del concepto del lugar y el rol que posee en la configuración del espacio urbano, así como sobre la responsabilidad profesional del arquitecto a la hora de configurar el espacio, nos parece oportuno subrayar algunas consideraciones previas de orden antropológico. En este sentido, al referirnos al concepto del lugar en la ciudad, se asume como punto de partida la noción de "persona humana" con la intención de esclarecer el origen mismo del 'habitar humano'. Bajo este marco contextual, es importante señalar desde el comienzo que el basamento en el que se asienta toda esta reflexión parte de asumir como marco antropológico una "visión personalista".

Esta visión personalista destaca la unidad indivisible del ser humano; es decir, la unidad entre "subjetividad personal" y "corporeidad humana". Max Scheler (2000), concretamente, distingue entre leib: es decir, corporeidad humana ("cuerpo vivido") y korper: cuerpo cosificado ("cuerpo exterior"). Según esto, el ser humano no sólo tiene cuerpo, sino que sobre todo es también cuerpo. Gracias a ese vínculo esencial original con la subjetividad personal, el cuerpo propio participa de una dignidad y un status antropológico prácticamente equivalente al de la subjetividad personal con la que está íntimamente ligado.

Partiendo de esta visión profunda de la persona, la calidad de vida del ser humano depende muy estrechamente de la calidad de vida dada a su corporeidad (al cuerpo vivido, existencial, personal). Por esta razón, es fundamental disponer de espacios o "lugares" idóneos para nuestro cuerpo que permitan encontrarnos con nosotros mismos (pensar, auto-conocernos) o comunicarnos con otras personas (gozar de relaciones interpersonales familiares y comunitarias), algo — por supuesto- mucho más importante que contar simplemente con ciertos espacios que, aun facilitándonos bienestar corporal externo, frecuentemente no ayudan o incluso dificultan en la práctica humanizarnos.

\section{La persona humana: un lugar y espacio a su medida}

Habitar no es sólo vivir, nos dice Caturelli (1984), si por vivir se entiende al acto de alojarse de forma meramente somática o externa como lo realiza cualquier animal. 'Sólo el ser humano habita'. Más aún, este filósofo ha escrito muy certeramente en su "Metafísica del habitar humano", que el "habitar es un acto propiamente humano, que implica a todo el hombre, con la totalidad de su naturaleza, que no es puramente espiritual sino también corporal. Por ello, porque el hombre habita, necesita edificar su casa como lugar físico de su habitar (...) [Así]: "Quienes hacen su casa o quienes adecuan a sí mismos la casa que les toca... hacen participar al edificio de su habitar más profundo" (p. 23).

En este sentido, el mencionado autor, hablando del habitar y de la necesidad del ser humano de construir su lugar, sostiene que la persona construye su casa como "inevitable condición física de su habitar" no teniendo sentido, así, un razonamiento inverso, pues tener "habitación o casa física, es consecuencia del habitar humano. Es muy posible que se relacione, superficialmente, esta reflexión sobre el habitar humano con la doctrina de Heidegger", explica Caturelli, y más adelante sugiere que la "casa sólo existe porque el habitar del hombre la 
requiere por su naturaleza corpóreo-espiritual" (p. 23-24). En este contexto, la casa es la respuesta a la necesidad más profunda del habitar del ser humano. Asumiendo esta dimensión honda del habitar y recordando que la persona es una unidad singular entre subjetividad y corporeidad, se puede concluir que "el cuerpo es el 'lugar' original en donde 'habita' la subjetividad personal" (Véase Figura 1).

De la misma forma, Caturelli subraya que "la casa o el edificio que el hombre hace se comporta como acto segundo y condición física del habitar metafísico del hombre, al poner de relieve y expresar de algún modo, la totalidad del ser del hombre" (p. 23). Incluso Bollnow $(1969,119)$ explica que "habitar no es una actividad cualquiera al lado de otras muchas, sino que es una característica esencial de la persona que determina su relación con el mundo en total", pues mediante el habitar el ser humano puede llegar a su plenitud personal.

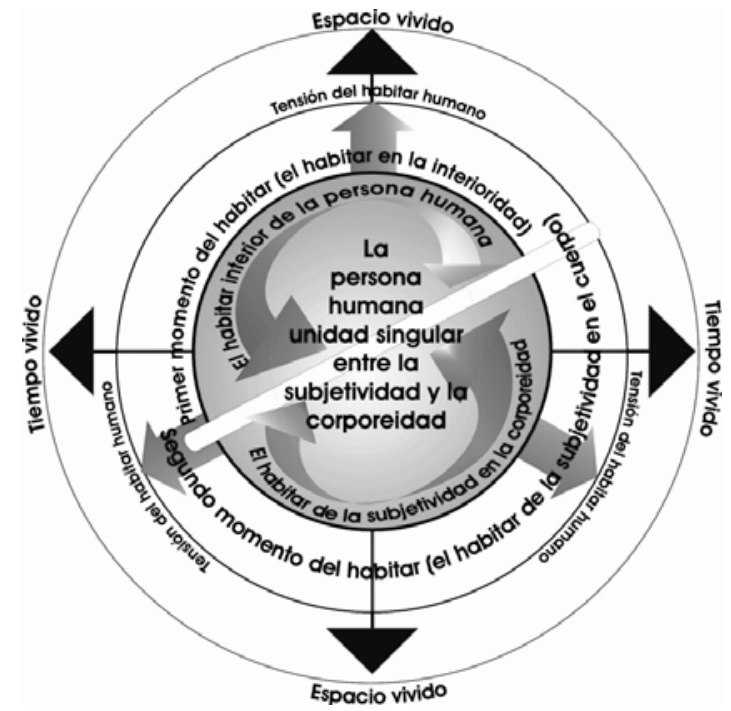

Figura 1: El origen del habitar: los dos momentos del habitar humano.

Fuente: Elaboración propia

En este sentido, el "lugar" es —recordando la relación existente en el ser humano entre 'subjetividad-corporeidad'- el "espacio vivido" con profundidad por la subjetividad personal de cada uno; un espacio en el que uno nota que forma parte (de algún modo) del propio ser (es decir, con el que se siente identificado); un espacio con el que uno tiene una relación prolongada (es decir, que forma parte de su propia biografía o historia personal); un espacio en el que abundan las relaciones con sus elementos materiales o personales (vinculación con el entorno). De este modo, el prototipo de "lugar" es el "hogar": el espacio-lugar en donde la subjetividad está llamada a sentirse más 'identificada', el más conformador de la propia 'biografía-historia' de la vida personal, el más íntimo espacio a la hora de favorecer las relaciones con su entorno: con las cosas materiales de ese lugar y, sobre todo, con las personas que lo habitan y con las que se está llamado a trabar unas relaciones de intimidad, a través del dialogo, de la comunicación humana (Véase la Figura 2). 


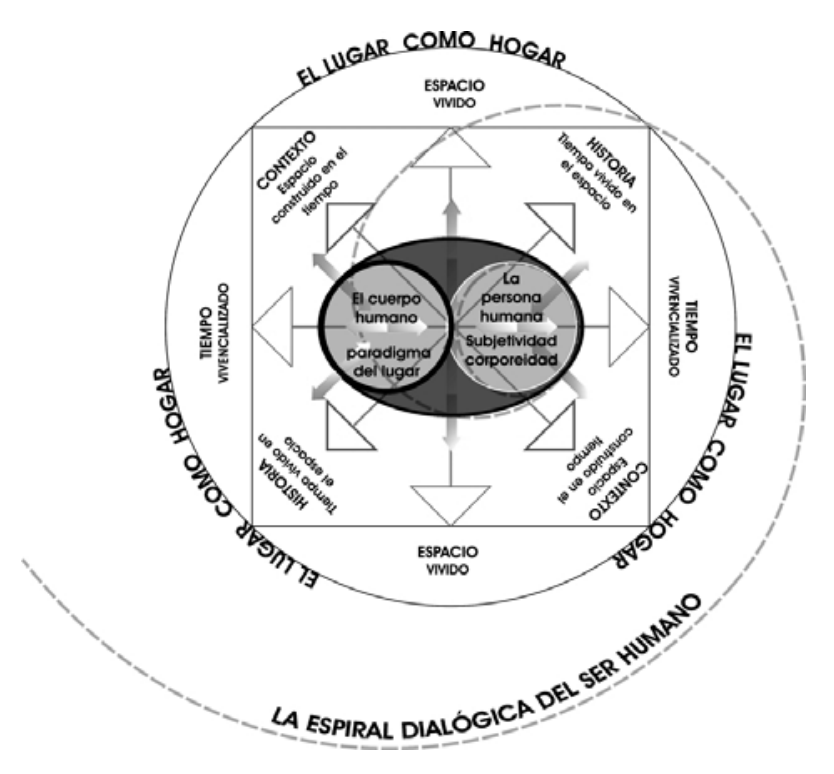

Figura 2: El lugar como hogar; Nota: la interacción con otros lugares a consecuencia de la cualidad comunicativa del ser humano. A partir de esta condición dialógica de la persona se desarrolla la apertura (la espiral dialógica) hacia otros lugares, haciendo posible la configuración del espacio urbano de la ciudad.

Fuente: Elaboración propia

Mi cuerpo es el 'lugar' original en donde 'habita' mi subjetividad personal (es decir, el "lugar existencial" espacial... de mi "subjetividad personal" interior). Desde este presupuesto básico y, por extensión, también mi casa, mi porción de ciudad más vivida, mi ciudad —entendidas como 'extensiones construidas' de mi cuerpo- están llamadas a ser verdaderos 'lugares' construidos para que 'habite' mi ser personal... y me humanice con plenitud, desde los aspectos más materiales hasta aquellos morales y espirituales más elevados. Asimismo, el "lugar" es el 'espacio existencial' (humanizador o personalizador) del ser humano, a diferencia del "espacio abstracto... o físico" (frío), es decir, de los no lugares. O, tal como lo expresa Caturelli (p. 23): "el hombre pragmatista y activista que ha derramado fuera su interioridad metafísica, apenas si se aloja en un lugar (sea el que fuere) perdiendo el encanto y la profundidad del habitar, (...) al trocarse en una yuxtaposición planificada de lugares de mero alojamiento".

\subsection{Ser humano y espacio urbano: la idea del lugar en la ciudad}

El ser humano construye su casa como inevitable condición física de su habitar. Este habitar íntimo de la persona, es decir, el lugar — materializado en el ámbito de la casa- da cobijo a la comunidad primera, otorgando así una residencia a la célula básica de la sociedad: la familia. En este contexto, Bollnow (1969), hablando de las condiciones de la habitabilidad, explica que la casa, concebida como espacio de protección y cobijo de la persona, no puede ser entendida exclusivamente como ámbito para que habite solitariamente el individuo. El habitar, y por ende su lugar primario, la casa, debe ser interpretada desde un habitar en comunidad, pues la vida 
del ser humano se materializa en familia. La historia de vida comunitaria del hogar desarrollada en una atmósfera de intimidad tiene su referente primero en el hogar, en la casa.

Desde una perspectiva similar Caturelli (1984) subraya que la casa, como la habitación física - arquetipo del habitar de la subjetividad en la corporeidad-, adquiere su significado en el hogar; de ahí su palabra originaria, domus, cuyo concepto también se remite al de familia, al de templo... Incluso, él nos explica que la familia requiere de una casa, de un domicilio como resguardo de la intimidad de su habitar. Por esto, dice que el "habitar supone intimidad, y la intimidad exige la interioridad". Además, "la familia no se basta a sí misma totalmente", por lo que "la intimidad de su habitar se religa a las otras familias" (pp. 23-24)

De esta manera, "el bien propio de la familia — sigue explicando Caturelli- no es el bien del padre más el de la madre y el de los hijos, sino un todo virtual, es decir, un bien común que es diverso del de cada uno de los singulares, al cual cada uno se subordina y que es el mejor bien de cada uno. Luego, existe un hilo conductor que liga el habitar de la familia, su bien común y el bien común y el habitar de las otras familias. Y como este bien no basta para realizar el fin de la familia, necesariamente se religa —en lo que tiene de común- a las otras familias. Cada familia, por eso, no sólo implica lo más íntimo del habitar humano, sino que lo religa al habitar de las otras en lo que tienen de común". Expresado de otra forma, podría decirse que el ser humano para poder ser necesita del habitar colectivo que tiene como base el bien común de la comuna, constituida por los moradores que la habitan. Así, en la medida que la comuna y sus ciudadanos posibilitan el habitar singular de la persona humana, crean el habitar urbano. De ahí que este autor subraye que "en cuanto habitar humano, todo habitar es, en el fondo, habitar urbano". Este supuesto es fundamental pues la hipótesis general que guía esta reflexión es que el ser humano se hace aún más pleno cuando - trascendiendo su círculo individual: el del propio lugar-hogar- llega al habitar urbano, en el que prima la comunicación y la comunidad.

Si la casa es el habitáculo físico del habitar humano, los edificios de una ciudad están llamados a ser la respuesta física del habitar colectivo de una sociedad, que —orientada al bien comúnpermite la realización del habitar más humano de sus ciudadanos. Urbs, explica Caturelli, significa la comunidad de moradores que la constituye, y como acto segundo la materialidad por la que está hecha. Es decir, representa el habitar urbano que se materializa en la dimensión física de la ciudad. Por esta razón, la ciudad está llamada a ser un espacio en el que habite el ser humano, del mismo modo que lo es la corporeidad humana en la que habita primariamente la subjetividad personal. Por el contrario, cuando la ciudad, en su globalidad, o en algunas partes de ésta no permiten el habitar, solo puede decirse que posibilita el alojamiento en espacios que se materializan en 'no lugares'.

\subsection{Del lugar al no lugar: la ciudad deseada}

En la unidad esencial entre la subjetividad y la corporeidad del ser humano radica el origen del habitar humano, insistiendo de nuevo aquí que es el propio cuerpo el lugar original en el que habita la subjetividad personal. A la par, como se ha visto, el ser humano construye su casa como "inevitable condición física de su habitar", es decir, como "acto segundo" del habitar originario como persona. Sin embargo, el lugar más próximo al ser humano, después de su corporeidad, es el hogar, el lugar por antonomasia, en donde el espacio es vivido con 
profundidad por la subjetividad personal, en donde uno nota que forma parte de sí mismo, del propio ser (el lugar como espacio propio... de identidad). En el ámbito del hogar el ser humano siente que las cosas que le rodean son parte de su propia historia, de su biografía personal; hay una abundante relación con los elementos materiales o personales relacionados con el entorno (el lugar como espacio histórico y relacional).

Así pues, el prototipo del lugar — como ya se ha dicho anteriormente- podemos decir que es el hogar. Sólo en un segundo momento lógico, las calles que lo rodean, el barrio en el que se inscribe, la ciudad en su conjunto, están llamadas a ser vividas como extensiones de mi corporeidad, es decir, y en cierta medida, como extensiones del hogar o como un hogar de grandes dimensiones (Véase la Figura 3). Recordemos lo dicho en párrafos anteriores, el 'lugar', al ser un espacio vivido por el ser humano como parte de sí mismo, se transforma en espacio existencial —lugar humanizado, personalizado-, a diferencia del espacio físico (frío y abstracto) en donde el ser humano ha derramado su interioridad más honda, alojándose simplemente de forma externa y transformando así los lugares en no lugares; espacios estos últimos en los que la persona humana ya no habita sino que se limita a alojarse, como ha señalado Caturelli (1984).

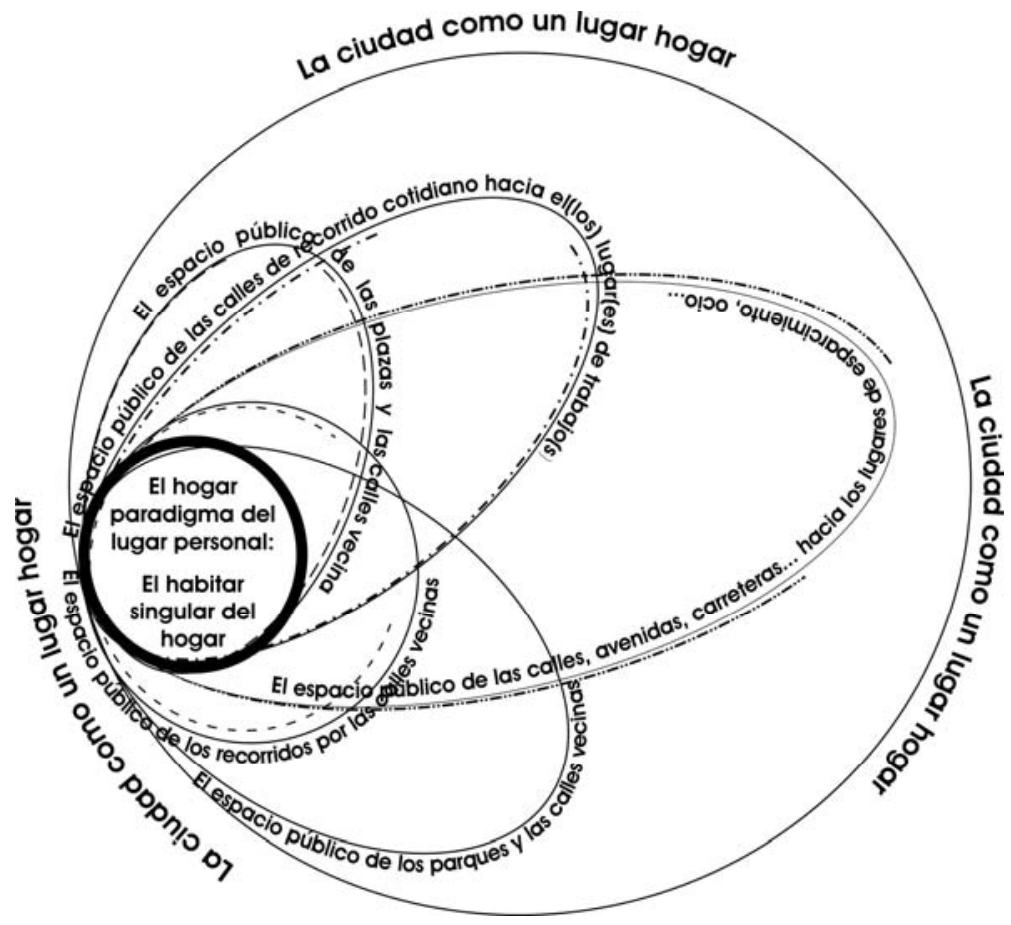

Figura 3: La ciudad como un sistema de lugares-hogares

Fuente: Elaboración propia 
Por otra parte, en "Arquitectura y narratividad" Paul Ricoeur (2002) sugiere, que el lugar no sólo es el envolvente primero (el hueco) donde poder "establecerse", como lo entendía Aristóteles. Más bien el lugar, según este autor, es un ámbito que se construye como fruto de una dialéctica entre dos estados de la persona: el refugio y el desplazamiento. Precisamente, el espacio de la ciudad es en parte el resultado de ambos movimientos. Sin embargo, estos movimientos no son siempre vividos como una extensión de la corporeidad humana a través de los lugares. Michel de Certeau (1996) señala con precisión que el lugar "se organiza a partir de la relación entre el lugar de donde se sale (un origen) y el no lugar que produce (una manera de 'pasar')". La experiencia del vagabundeo — nos dice este autor- "multiplica y reúne la ciudad, haciendo de ella una inmensa experiencia social de privación de lugar" (p. 116).

De esta forma, si el espacio urbano no es vivido en plenitud por el ser humano (habitado, existencializado), la ciudad puede convertirse, en algunos de sus ámbitos o en la totalidad de sus espacios, en un no lugar, en una yuxtaposición de sitios anónimos, deshumanizados, en verdaderos guetos urbanos. Esto también sucede, dice de Certeau, en muchas de nuestras ciudades, al vivir física o externamente en ellas pero sin llegar a hacerlo de la manera propia habitando en un lugar - vivir en las ciudades- sintiéndonos y buscando integrarnos desde el hogar (arquetipo del lugar), pasando por nuestras calles vecinas, el barrio, hasta la ciudad. Haciendo esto se deja de lado ciertas actitudes de escape —el vagabundeo- que buscan vivir imaginariamente en otros lugares —lugares soñados_, o simplemente no viviendo — sin arraigarse en el lugar- los ámbitos cotidianos como parte expandida del espacio mas personal del hogar.

En este sentido, es importante señalar que la existencia de lugares en la ciudad permite al ser humano arraigarse, al poder contar con espacios pensados (proyectados) y construidos a su medida. En estos ámbitos es posible existencializar la vida de la persona al configurarse como lugares antropológicos, sugiere Marc Augé (2004). Si un lugar puede ser un sito con identidad, relacional e histórico, "un espacio que no puede definirse ni como espacio de identidad ni como relacional ni como histórico, define un no lugar", explica este autor (p. 83). Asimismo, señala que los no lugares "son la medida de nuestra época; medida cuantificable que se podría tomar adicionando, después de hacer algunas conversiones entre superficie, volumen y distancia, las vías aéreas, ferroviarias...", y toda una multiplicidad de ámbitos que van entretejiendo una compleja red de "cables o sin hilos", que producen una comunicación — contacto- tan extraña que nos acerca — pero que no nos comunica_ - "al individuo más que con otra imagen de sí mismo" (pp. 84-85).

El citado autor comenta además que los no lugares se caracterizan por una multiplicidad de rasgos típicos de la cultura actual; uno de ellos la trasgresión de la palabra a través del uso ambiguo que se hace de ella. Podría decirse que si la palabra es al lugar lo que la actividad humana es al espacio cuando es vivido, la trasgresión del significado, generador de no lugar, más que desarrollar espacios existenciales (ámbitos en donde el ser humano pudiese arraigar) genera sitios anónimos en donde la preponderancia de los desplazamientos — personas, mercancías e informaciones- sólo adquieren sentido en el puro tránsito y en la velocidad. En estos ámbitos, el espacio que se construye no es un sistema, una relación de lugares, sino más bien sitios testimonios de flujos, o más bien, no lugares convertidos en espacios de flujos. 
Sin embargo, un lugar se caracteriza por ser ámbito con significado, por tener un 'sentido inscripto', por poseer un 'carácter simbólico', y además por haber sido puesto en acción ese sentido inscripto, explica Augé. Por el contrario, el no lugar se identifica por ser un espacio exclusivamente simbolizado. En ámbitos con estas características lo que prevalece -otro rasgo particular de los no lugares- es la soledad despersonificada en conexión silenciosa (los espacios de los aeropuertos, de las autopistas, de los centros comerciales, etc.). Todo lo contrario ocurre en los lugares en donde es posible generar recorridos, itinerarios, pocos sujetos a los horarios precisos y estrictos, tanto de salida como de llegada. A diferencia de esto, en un no lugar reina la actualidad y la vigencia del tiempo presente; un tiempo que tiende a la búsqueda de lo instantáneo. En estos sitios se vive en el presente, dice Augé, y continúa explicando que en estos ámbitos el espacio parece como si estuviese "atrapado por el tiempo, como si no hubiera otra historia más que las noticias del día o de la víspera, como si cada historia individual agotara sus motivos, sus palabras y sus imágenes en el stock inagotable de una inacabable historia en el presente" (pp. 107-108). De este modo, el tiempo en el espacio de los flujos, es decir, en los no lugares, a diferencia del tiempo existencializado en el espacio (vivido en un lugar), no es un tiempo vivencial, sino más bien un tiempo cosificado.

Todo esto, nos hace pensar en la necesidad imperiosa de contar con verdaderos lugares en las ciudades que mitiguen la existencia de tiempos y espacios de anonimato e incomunicación propios de los no lugares. Puede resultar conveniente recordar que, la presencia de "lugares" permite al ser humano vivir con plenitud, ejerciendo el acto de habitar, pues, a diferencia del mero alojamiento sicosomático de los animales, "el ser humano es sólo quien habita", tal como comenta el filósofo Caturelli: "para el hombre y sólo para el hombre, ser es habitar". Acto -el de habitar - que ha de proyectarse desde el interior de la persona —en armonía consigo mismo- hacia el espacio cotidiano de la casa, de aquella porción de ciudad más vivida por uno, en definitiva, de la ciudad donde uno vive. Por todos estos motivos, parece oportuno dirigir nuestros esfuerzos a crear urbes que puedan ser concebidas y vividas como 'extensiones construidas' de nuestro cuerpo, como verdaderos 'lugares-hogares', en donde pueda ser posible 'habitar'. Si esto es así, entonces la persona podrá humanizarse no sólo a nivel material sino sobre todo lograr anímicamente desarrollarse con plenitud.

\section{La arquitectura y el arquitecto: su responsabilidad profesional}

El arquitecto tiene la posibilidad de ejercitar una virtud práctica a través de la creación de un proyecto, explica Muntañola (2001). Asimismo, él sigue diciendo que a lo largo del ejercicio proyectual lo que debe hacer el arquitecto, ejercitando su ética, es crear un modelo a partir de "prever la forma física (sin ser el constructor), el uso social (sin ser el usuario) y la estética y significado cultural de la obra (ciudad o edificio) sin poder verla nunca acabada" (p. 116). Además, este autor señala que la actividad del arquitecto es compartida por el pedagogo y el legislador. Todos, constructores de un proyecto social, edifican el futuro de una sociedad. El legislador estableciendo leyes, el pedagogo formando a la persona y el arquitecto dando forma, a través del proyecto arquitectónico, a la interacción (a la comunicación) social de una comunidad. 
Resulta muy significativa la relación descrita con tanto acierto por Aristóteles al comparar el acto arquitectónico de proyectar la ciudad con el que posee el legislador al "prever el futuro" desde el propio proyecto. En este sentido, buena parte de la labor profesional del arquitecto, de su sentido y finalidad, depende de la "visión social y cultural", de la "educación que él promueve, a través del proyecto arquitectónico. Muntañola explica que el "equilibrio emotivoracional, artístico-científico, social-físico, etc. (todo habla de procesos sostenibles) cabe valorarlo como un camino para convivir y para conseguir un medio social y físico mejor para todos". Fin homónimo para la pedagogía y la actividad del legislador. Asimismo, subraya además que si con el proyecto se consigue favorecer la construcción social y cultural es porque se han podido articular las cualidades individuales del proyecto y la "capacidad colectiva de representar un diálogo" (p. 116).

Así, cuando se proyecta, es decir, cuando se diseña sin esa premisa de reconstruir un diálogo social, la consecuencia es la generación de unos arquitectos autistas, unos "genios solitarios" que no se comunican con la sociedad. El citado autor añade, haciendo referencia a Platón, que las "casas escriben las leyes sociales sobre las paredes de nuestras ciudades" (p. 116) y, que los niños podrían comprender que el espacio de las urbes y las leyes se encuentran inscritas en el lugar ${ }^{1}$. Por eso, tanto la ciudad como la arquitectura, en cuanto hechos sociales, se encuentran íntimamente unidas a las transformaciones culturales que se van suscitando a partir de los cambios físicos, ecológicos históricos... Cambios que, por otra parte, deberían se "transparentados" tanto en las personas como en las formas de la ciudad.

Tener en cuenta el lugar y su forma como medio capaz de desarrollar la comunicación humana (la socialización de una comunidad) nos permite comprender y proyectar el orden social en la materialidad del espacio arquitectónico a través de un diálogo entre la cultura y el proyecto de un lugar desde una virtud práctica arquitectónica. Dicho de otro modo, es decir, mediante el ejercicio de una moral práctica o virtud sabia en la proyección del espacio para vivir, de un lugar hogar, habría que saber en qué consiste el ejercicio de este hábito práctico de la arquitectura a fin de adecuar la enseñanza y las prácticas del arquitecto hacia estos objetivos. Muntañola (2000), al hablar sobre la "dimensión ética de la topogénesis", explica la moral como arquitectura del pensamiento aristotélico e insiste que tanto la ética como la política son partes de una misma realidad, pues ambas necesitan para su ejercicio "de lo moral".

Asimismo, este autor insiste en todo un debate sobre la arquitectura como práctica de una virtud-sabia que posee enormes repersecuciones. Por una parte, aquella se encuentra llamada a construir lugares más allá de una corriente estilística imperante en la arquitectura o de un estilo en particular. De este modo, nos dice el autor, "el proyecto ético de Aristóteles acaba con un paradigma arquitectónico: la suma virtud y sabiduría se dan en un saber comportarse "arquitectónico", es decir, en un saber comportarse que es capaz de reflexionar sobre el pasado y el presente, conformando un futuro mejor para todos. $Y$ esto es precisamente lo que se necesita para prever el futuro de una ciudad en la cual todos vivan con comodidad, belleza y seguridad" (p. 67). En definitiva, la creación o la aproximación, siempre dinámica y permanente

\footnotetext{
${ }^{1}$ Muntañola (2003) explica, hablando del concepto de transparencia en la arquitectura, que el ser humano necesita participar desde el proyecto, y más aun, en la vivencia del espacio a "partir de un equilibrio entre sensación y conocimiento" (p. 37-38). Tensión que el filósofo griego Platón la denominaba con el término Khôra; una fuerza que podría decirse es el principio del mundo. Además, en otro escrito sobre "Educación y arquitectura: el proyecto como estímulo para la inteligencia" Muntañola (2004) sostiene que la Khôra se estableces como "base del espacio y lugar humano, articula el cosmos con la historia, la naturaleza biológica con la naturaleza social" (p. 116).
} 
del desarrollo de unos espacios para vivir, necesita no sólo de las "leyes inmutables de las piedras" del hacer arquitectónico, sino también de la practica ética desde la formulación del las leyes por parte del legislador.

A la labor del arquitecto y legislador se sigue la necesaria e irremplazable tarea del profesor (del pedagogo), formador de la persona desde la más temprana edad, hasta la educación de arquitectos llamados a ser y, por tanto a estar capacitados para resolver la complejidad del lugar indagando en la complejidad del propio ser humano y en el contexto donde la persona vive. Finalmente, Muntañola (2001) subraya la necesidad de educar en la arquitectura "integrando el espacio y el tiempo con todas las otras disciplinas, haciendo que todas sean cualitativamente 'arquitectónicas', es decir: éticas. Paradojas de la historia, pero no absurdidades; la arquitectura, piedra de toque de la ética, es justamente, hoy, uno de los campos más claros de la especulación, el poder de mafias duras y puras y el campo de batalla de la violencia por un lugar para vivir" (p. 120).

\section{Conclusiones}

A modo de conclusión, parece oportuno subrayar que la actividad profesional del arquitecto (su responsabilidad profesional) debería estar orientada a la construcción de lugares 'a medida del ser humano'; un tipo de construcción que contemplaría así las necesidades humanas desde un enfoque global. Dicho esto de otro modo: lo realmente importante no es sólo orientar la actividad arquitectónica a la resolución de aspectos funcionales y utilitarios, sino también a la creación de ámbitos capaces de sensibilizar a las personas a través de formas espaciales que expresen la armonía, la belleza... Para lograr este cometido, habría de esforzarse en captar las "razones del lugar" (la historia que lo envuelve, su cultura, sus valores simbólicos, etc.) buscando para ello situarse en la mentalidad viva del usuario en su tarea proyectiva y constructiva.

Esta creación del lugar que el arquitecto busca hacer, intentando colocarse en el lugar de quien lo va a vivir, nos hace pensar en la responsabilidad de éste a la hora de preservar, renovar o crear las condiciones óptimas que permitan el desarrollo del habitar humano. Creación que recuerda también el valor del lugar como puente entre la historia y el ser humano, válida para el espacio singular de la vivienda, para los sitios dedicados a las actividades laborales o para el espacio público de la ciudad. Al hilo de este pensamiento, el arquitecto debería, ya desde el proyecto, ejercer su ética, creando un modelo que prevea la forma física del espacio sin ser él su constructor, indagando el uso social que se le dará al lugar, sin que como arquitecto sea el propio usuario, desarrollando una estética a partir de incorporar significado cultural a la obra (edilicia o ciudadana), aun en el caso de que no la vea terminada.

Asimismo, habría de tenerse en cuenta que uno de los inconvenientes más importantes con que se enfrentan los arquitectos, mayoritariamente dedicados al proyecto, es su escasa implicación a la hora de 'crear ciudad'. En efecto, la construcción de la ciudad está en manos de promotores, especuladores inmobiliarios, etc. Sin embargo, la falta de un planteamiento teórico claro que oriente el proyecto arquitectónico, el insuficiente trabajo multidisciplinar en el campo de la arquitectura y el urbanismo, y la escasa integración de la gestión del urbanismo, 
tiene como resultado distintos tipos de actuaciones urbanas que no logran constituir un todo unitario; es decir, da lugar a actuaciones que no favorecen la creación de ciudad. Se entiende así que la actividad del arquitecto quede actualmente recluida, en el mejor de los casos, a actuaciones particulares a través de la realización de proyectos puntuales.

Finalmente, convendría señalar nuevamente, en cuanto a la responsabilidad profesional del arquitecto, que ésta no sólo debería restringirse a los límites que una ley o normativa prescribe. Ciertamente, nada de lo expuesto anteriormente puede resultar posible si el arquitecto no llega a asumir, a nivel de conciencia y sensibilidad, una 'teoría del lugar' como la que se ha intentado esbozar en este artículo. Además, es necesario y urgente que el arquitecto reasuma su lugar en la sociedad atendiendo a varias razones. Entre ellas recordamos aquí tres. La primera es que el arquitecto, desde el proyecto y la construcción más discreta, debe sentirse "constructor de ciudad", en vez de un simple 'tecnócrata'. La segunda razón a tener en cuenta es que el arquitecto ha de saber captar las "razones" del lugar (la historia envolvente, su cultura, sus valores simbólicos, etc.), intentando para ello situarse en la "mentalidad viva del usuario" al acometer su tarea proyectiva y constructiva del espacio construido, sea éste singular 0 colectivo-ciudadano. La tercera razón se dirige a concienciar al arquitecto a cambiar de mentalidad; experimentar una formación y trans-formación permanente. Cambio que ha de empezar desde la propia preparación del arquitecto, en las escuelas superiores de arquitectura universitarias, así como también a los Colegios Profesionales de Arquitectura. Sin esa mentalidad sólidamente con-formada, lo más usual que puede esperarse del arquitecto es que se limite a proyectar y a realizar con eficacia construcciones firmes, útiles, e incluso atractivas.

A la luz de todos estos comentarios, la tarea del arquitecto se perfila más interesante y responsable: su actividad consiste ahora, tanto a nivel edilicio como urbano, en crear verdaderos lugares a la medida del ser humano, dirigiendo los esfuerzos a la construcción de espacios y temporalidades que humanicen a las personas 'construyendo ciudad'. 


\section{Bibliografía}

AUGÉ, M. (2004): Los no lugares. Espacios del anonimato. Una antropología de la sobremodernidad, $8^{\mathrm{a}}$ ed., Gedisa, Barcelona.

BOLLNOW, O. F. (1969): Hombre y espacio, Labor, Barcelona.

CATURELLI, A. (1984): "Metafísica del habitar humano", en aa.vv. (1984), La ciudad. Su esencia, su historia, sus patologías, Fades Ediciones, Buenos Aires.

CHILLIDA, E. (2001): Museo Chillida Leku, Textos escritos por Mitxel Esquiaga, Chillida-Leku S.L, Gipuzkoa.

DE CERTEAU, M. (1996): La invención de lo cotidiano: un arte de hacer, Universidad Iberoamericana, A.C., México.

MUNTAÑOLA THORNBERG, J. (2000): Topogénesis. Fundamentos de una nueva arquitectura, Ediciones UPC, Barcelona.

MUNTAÑOLA THORNBERG, J. (2001): "La Arquitectura y Educación: Espacio, Sociedad y Cultura", en la revista Polis Científica, Ed. Universidad Nacional del Litoral, Santa Fe, Argentina.

MUNTAÑOLA THORNBERG, J. (2003): La arquitectura de la transparencia (El espacio humano), Arquitectonics, Edicions UPC, Barcelona.

MUNTAÑOLA THORNBERG, J. (2004): "Arquitectura, educacion y dialogía social, en Revista española de pedagogía, Año LXII, N. ${ }^{\circ} 228$, pp. 221-227.

RICOEUR, P. (2003): Arquitectura y narratividad, Arquitectonics, Edicions UPC.

RICOEUR, P. (2002): "Arquitectura y narratividad", en la revista Arquitectonics, Arquitectura y hermenéutica, Ediciones UPC, Barcelona.

SCHELER, M. (2000): El puesto del hombre en el cosmos, _Alba, Barcelona. 